\title{
FILOSOFIA, POESIA E RESISTÊNCIA: SOBRE A UNIDADE ENTRE EPISTEMOLOGIA E MILITÂNCIA POLÍTICA EM TEMPOS DE CRISE
}

\author{
PHILOSOPHY, POETRY AND RESISTANCE: \\ ABOUT UNITY BETWEEN EPISTEMOLOGY AND MILITANCY \\ POLITICS IN TIMES OF CRISIS
}

Otacílio Gomes da Silva Neto ${ }^{1}$

\section{RESUMO}

A crise social vivenciada pelos brasileiros tem dado margem a medidas governamentais de caráter suspeito. Impulsionados por setores empresariais, midiáticos e do agronegócio, tais medidas também chamadas de "reformas", têm sido apressadas por membros do poder legislativo em conluio com o executivo. Essa trama foi montada no auge da crise do governo da presidenta Dilma o que levou ao impeachment do seu mandato. Passados alguns fôlegos da usurpação do poder executivo, boa parte dos brasileiros começa a perceber que esse processo foi uma farsa montada pelas camadas privilegiadas com o apoio ideológico da grande mídia. Diante disso, a meta desse trabalho é o de elaborar uma reflexão crítica do cenário brasileiro endossando leituras alternativas àquela oferecida pela mídia oficial. Partiremos de uma problematização envolvendo o conceito de crise a partir de Bobbio (2004) e Santos (2007) para entender as razões da ofensiva das classes privilegiadas que comandam o país. Em seguida, a partir de Gramsci (2011) e Freire (2006), retomaremos o conceito de conscientização cujo sentido vislumbra o ato de conhecer como resistência à opressão via o engajamento político. Concluiremos o trabalho resgatando, a partir de Arendt (2002), a desgastada arte da política como instrumento de humanização e inclusão social.

Palavras-chave: crise; conhecimento; resistência; política.

\begin{abstract}
The recent social crisis in Brazil has given political players of a certain leaning the excuse they needed to make political maneuvers of a suspicious nature. Backed by corporations, the mainstream media and agribusiness, such measures, which have also been called "reforms," have been hastened by members of the legislature in collusion with the highest-ranking government leaders. Their scheme was hatched at the height of the crisis of President Dilma's government and culminated with her impeachment. Shortly after the usurpation of the executive branch, much of the Brazilian public began to perceive it as a farce created by the privileged classes with the ideological support of the mass media. In light of this context, the goal of this paper is to reflect critically on the Brazilian scenario, endorsing alternative interpretations to those espoused by the mainstream media. The paper begins with the problematization of the concept of crisis in Bobbio (2004) and Santos (2007) in order to gain insight into the reasons behind of the offensive waged by the privileged classes in command of Brazil. Next the paper examines the concept of conscientization found in Gramsci (2011) and Freire (2006), which interprets knowledge as a means to resist oppression via political engagement. The paper concludes by recovering the concept of politics from the outworn view of it as an art to the understanding of politics, per Arendt (2002), as an instrument of humanization and social inclusion.
\end{abstract}

\footnotetext{
${ }^{1}$ Doutor em Filosofia na área de concentração em ética e filosofia política pelo Programa Integrado de Doutorado em Filosofia (UFPB-UFPE-UFRN). Professor de filosofia da educação da Universidade Estadual da Paraíba. Email: otacilio.uepb@hotmail.com
}

Revista Debates Insubmissos, Caruaru, PE. Brasil, v.1, n.1, jan./abr. 2018. Endereço: https://periodicos.ufpe.br/revistas/debatesinsubmissos/ 


\section{Revista 0 \\ Debates Insubmissos}

Keywords: crisis, knowledge; resistance; politics

\section{INTRODUÇÃO}

A nossa geração tem presenciado e convivido com tempos obscuros no Brasil. Ante o desemprego e a violência cada vez mais agudos, a nossa população assiste atônita à veracidade ou não da confissão de delatores, (des)informações midiáticas, verborreias de parlamentares, juízes e membros do executivo. Em meio a esse cenário caótico, oportunistas ligados ao grande capital empresarial e especulativo impulsionam o que eles chamam de "reformas" como salvação nacional, sorrateiramente apoiadas pela grande mídia. Contudo, para boa parte da população, trata-se de uma retórica difícil de acreditar em se tratando do espetáculo de horrores pelo qual os poderes da nossa República têm apresentado em tempos recentes.

Nesse contexto, defendemos que o ceticismo crítico aliado à resistência política ante a manipulação das classes obesas devem ser encorajados, pois não se pode esperar "pacotes de bondades" da maior parte desses agentes em curso. Em outras palavras, pretendemos estimular uma epistemologia que una conhecimento e ação para contrapor-se às retóricas de cunho reformistas que ocultam as garras do capitalismo financeiro globalizado. Para Freire (2011, p. 143): “Ao nível humano, o conhecimento envolve a constante unidade entre ação e reflexão". Os inúmeros problemas pelos quais passa o Brasil, exige de nós, membros da academia, posicionamentos que nos comprometam com a real situação vivenciada por nosso povo, nas regiões e comunidades nas quais fazemos parte.

O objetivo desse ensaio é propor um debate coletivo, aberto e dialógico, em vista de um engajamento político, alheio a fanatismos e manipulações partidárias, ou advindos dos grandes meios de comunicação. A nossa metodologia circunscrever-se-á no campo da investigação heurística por meio da pesquisa de produção e fontes bibliográficas. Portanto, para atingir o objetivo do trabalho, o nosso método partirá de uma reflexão sobre o que se 
chama de "crise" no Brasil atual em suas variantes econômica, política e social, tendo por base Bobbio (2004) e Milton Santos (2007).

Em seguida, analisaremos os atores vigentes focando na manipulação midiática, confusão entre poderes e na bestialização da maioria dos partidos e da política. Ressaltaremos a importância do conceito de conscientização a partir de Freire (2006) e Gramsci (2011) com o intuito de resistir à massificação, a partir de uma epistemologia ousada que nos inspira ao engajamento da realidade. Fundamentados em Hannah Arendt (2002), concluiremos o trabalho resgatando a importância da política enquanto produção humana em vista da inclusão social e da humanização.

\section{1. “CUIDADO: BURACO FUNDO": A CRISE IMBECILIZADA}

Uma das palavras mais pronunciadas nesse contexto caótico é “crise". Essa palavra passou a ser notória e em diversos ambientes é costumeiro se falar da crise política, econômica, ética, da federação, estados e municípios. Em volta da "crise" inúmeras retóricas convergem, sem que nenhum protagonista da política, da informação ou da economia se

interesse em ser o seu genitor. Cada um tem afirmado que o genitor da crise é o outro: a gestão da presidenta Dilma e o PT, o cenário internacional, o "golpe" e os seus conluiados, a operação Lava Jato, a cultura do "jeitinho" brasileiro.

Logo após o impeachment da presidenta Dilma, a propaganda estapafúrdia em volta da retomada do crescimento começou a trabalhar. Uma centena de outdoors foi espalhada em grandes cidades e estampava a seguinte frase: “Não fale em crise, trabalhe!!!”. Frase citada pelo próprio Temer em seu primeiro discurso após a derrubada do Governo Dilma. Em outras palavras, não faria sentido falar em crise em tempos de Temer, como se os brasileiros fossem estúpidos e acreditassem nessas falácias ineficazes. Há uma historinha de cunho anedótico que acompanha essa frase. $\mathrm{O}$ homem que mandou colocar a placa com o tal dito, foi um certo senhor alcunhado de Joca. Ele era o dono do posto desativado em Mairinque, cidade localizada à beira da rodovia Castelo Branco em São Paulo, onde o letreiro foi encontrado por Temer. 
Procurado por despertar interesse após o discurso do mandatário, descobriu-se que o Joca estava preso por atirar anos antes em alguém devido a desavenças pessoais, bem como ele foi acusado de adulterar combustível naquele posto. $\mathrm{O}$ homem que fez o letreiro cognominado Nelinho, não recebeu nada pelo trabalho. E o mais irônico é quando Nelinho foi informado que a dita frase foi elogiada por Temer, aquele foi enfático ao afirmar que: "Os políticos estão com as frases boas, mas tinham que dividir a grana"². Belo mote. Para finalizar essa historinha real, Nelinho estava trabalhando em um novo letreiro que dizia: "Cuidado: buraco fundo" "3. As frases em destaque nesse subtópico bem que poderiam fazer parte de uma dessas poesias do absurdo. Ousemos, então:

Não fale em crise, trabalhe!!!

Os políticos estão com as frases boas, mas tinham que dividir a grana Cuidado: buraco fundo.

Muitos dos que foram para a rua exigir a saída de Dilma não tinham ideia do "buraco" no qual estavam entrando. Entendemos que esse fato pode ser considerado analogamente como um pequeno poema inserido em um livro anedótico que está sendo escrito por esse governo obscuro.

\section{CRISE: CONCEITO E PROBLEMATIZAÇÃO}

Conforme Pereira (1990, p. 808), a palavra "crise" vem do grego "krisis" e significa: “circunstância difícil". Passar por "crise” ou "circunstância difícil" nunca foi novidade para os milhões de brasileiros que sempre foram jogados na marginalidade. Obviamente, para os mandatários atuais, aqueles não são parte da solução, mas do problema. Contrariando os congressistas que votaram pela saída de Dilma, menos pelas ditas "pedaladas fiscais" e mais pela retórica ilusória do Brasil voltar a crescer, o que vemos é um espetáculo assustador para os mais pobres, ao passo que extremamente favorável para as classes obesas. Por exemplo, há

\footnotetext{
2 “Citada por Temer, placa 'não fale em crise’ fica em posto desativado”. Folha de São Paulo, 13 de maio, 2016.

${ }^{3}$ Id. Ibid.
} 
14 milhões de desempregados no país, conforme o $\mathrm{IBGE}^{4}$. Isso significa que há praticamente mais do que a população da Bélgica no Brasil, não apenas fora do mercado de trabalho, mas também sem crença no presente e sem perspectiva de futuro.

Bobbio (2004, p.303) entende o conceito de crise a partir de três fases, conforme citação: “[...] a fase precedente ao momento em que se inicia a Crise, a fase da Crise propriamente dita, e, por fim, a fase depois que a Crise passou e o sistema tomou um certo 'módulo' de funcionamento que não se identifica mais com o que precedeu a Crise". Conforme essa interpretação, a crise tem um status passageiro. Ela se situa entre uma e outra situações de normalidade.

Santos (2007) tem uma compreensão diferente sobre a crise no contexto do capitalismo globalizado. Para ele, a história do capitalismo foi construída a partir de períodos antecedidos e sucedidos por crises em meio a instantes de estabilidade. Contudo, na forma em que o atual capitalismo internacional se encontra, a crise é permanente, portanto, os períodos são perenemente acompanhados de instabilidade. Se a instabilidade é permanente, então a crise é estrutural, isso significa que há uma normatização da crise. Em outras palavras, há uma realidade política e econômica global na qual povos e nações devem se adequar, pois não há saída fora desse modelo. E essa mesma realidade histórica é caracterizada por uma crise perpétua, razão na qual os ajustamentos são necessários, conforme citação:

Então, nesse período histórico, a crise é estrutural. Por isso, quando se buscam soluções não estruturais, o resultado é a geração de mais crise. O que é considerado solução parte do exclusivo interesse dos atores hegemônicos, tendendo a participar de sua própria natureza e de suas próprias características (SANTOS, 2007, p. 35).

Dentro desse esquema, as saídas e os remédios advém daqueles que se beneficiam da crise, portanto não há remédio fora desse modelo. O poder do dinheiro aliado à informação são a garantia de que essa violenta estrutura se perpetuará, já que a manipulação advinda desse poder não se permite ser questionada por ousadias estranhas a ele. As tentativas de soluções não estruturais são logo atacadas veementemente, já que esses remédios uma vez aplicados supostamente gerarão mais e mais crise, logo, torna-se quase impossível ousar fora do "pensamento único" hegemônico. Para Santos (2007, p. 36):

4 “14 milhões de desempregados. É a 'retomada' do Temer”. Brasil 247, 29 de abril, 2017. 


\title{
soristat 0 \\ Debates Insubmissos
}

\begin{abstract}
O mesmo sistema ideológico que justifica o processo de globalização, ajudando a considerá-lo o único caminho histórico, acaba, também, por impor uma certa visão da crise e a aceitação dos remédios sugeridos. Em virtude disso, todos os países, lugares e pessoas passam a se comportar, isto é, a organizar sua ação, como se tal "crise" fosse a mesma para todos e como se a receita para afastá-la devesse ser geralmente a mesma. Na verdade, porém, a única crise que os responsáveis desejam afastar é a crise financeira e não qualquer outra. Aí está, na verdade, uma causa para mais aprofundamento da crise real - econômica, social, política, moral - que caracteriza o nosso tempo.
\end{abstract}

Entre a década passada e o início da atual, o Brasil viveu momentos de inclusão social e relativa expansão, bem como uma pequena melhora dos serviços associados à saúde e educação. Por exemplo, os gastos públicos em saúde saltaram de R\$ 28 bilhões em 2002 para R\$ 106 bilhões em 2013. Já em educação, os gastos em 2002 eram de R\$ 17 bilhões enquanto em 2013 chegaram a R\$ 94 bilhões. Enquanto que o Índice de Desigualdade Social no Governo de FHC teve queda de 2,2\%, no Governo Lula até o primeiro mandato do Governo Dilma, esse Índice teve queda de 11,4\%. A taxa de extrema pobreza em 2003 era de 15\%, muito acima dos $5,2 \%$ registrada em $2012^{5}$.

A verdade é que a avassaladora crise econômica internacional não tardou a bater às portas da nação tupiniquim. E ela veio com força entre o primeiro e o início do segundo mandato de Dilma. A crise internacional pegou um Brasil afogado em gastanças inúteis que unia: dos estádios padrão FIFA à Olimpíada no Rio de Janeiro, tendo, é claro, o aval dos principais Meios de Comunicação Social e os esquemas das empreiteiras. O PT pagou um preço caro quando se iludiu com as delícias do poder e incorporou as regalias da elite dominante. Astuto, Fernando Henrique cobrava a condição em dialogar com o Governo Dilma, se o PT reconhecesse seus erros. Embora aquele acadêmico presidente nunca fizera questão em reconhecer seus próprios equívocos. Errados são os outros.

Não tardou para que a crise econômica tivesse consequências na política. Era preciso achar um culpado para a crise, então a culpa caiu no PT de Lula e Dilma. Com garra, esta última resistiu como pode. Mas, o rolo compressor que unia o empresariado, banqueiros, os donos do agronegócio, as famílias ricas detentoras dos principais Meios de Comunicação

\footnotetext{
5 “Dados Governos FHC/PSDB e Lula-Dilma/PT por Hildegard Angel, jornalista”. LeonardoBOFF.com, 11 de abril, 2004.
} 
capitanearam um grande número de deputados oportunistas liderados pelo astuto, e não menos megalomaníaco, Eduardo Cunha.

Foi assim que o Brasil assistiu ao show de horrores naquela noite de 17 de abril de 2016. O processo no senado foi um jogo de cartas marcadas. Uma vez que a presidenta Dilma foi descartada, o alvo até então tem sido Lula. Há dois anos que assistimos na TV, jornais, rádios e agências de notícias um verdadeiro linchamento contra Lula e o PT.

\section{CRISE E MANIPULAÇÃO MIDIÁTICA}

Para o atual governo, em meio à crise, a necessidade em encontrar soluções para os problemas sociais e econômicos no atual cenário têm servido de escusa para outras finalidades. O setor empresarial, maior fiador do governo Temer e da grande massa de deputados, tem a chance de implantar medidas cujo objetivo é o sucateamento e o desmonte do setor público, já iniciado na era do governo de Fernando Henrique, em vista de uma geração de dividendos para alimentar a agressiva máquina do lucro. O problema é que com a descoberta do fraudulento esquema de campanha no qual envolve quase todos os partidos, o congresso perdeu a sua credibilidade.

O esquema envolve um ilícito financiamento público de campanha num conluio que arrasta empresas como a Odebrecht, e políticos - até onde sabemos -, porque há suspeitas que membros do poder judiciário também estão envolvidos. Trata-se de uma trama bilionária na qual as empresas investigadas têm proteção e benefícios em contratos firmados com o setor público, por meio de políticos e partidos facilitadores. Os indícios levam a crer que o descarte da presidenta Dilma tinha como uma das metas "estancar a sangria", nas palavras do senador Romero Jucá. Em outras palavras, era preciso retirar Dilma do poder para que os políticos e empresas envolvidos no escândalo pudessem sair incólumes.

Toda essa trama nacional transformou os três poderes - executivo, legislativo e judiciário - num monstro de três cabeças, cada uma querendo engolir a outra. Em consequência da artimanha que levou à queda de Dilma, nós temos hoje um executivo miúdo 
e medíocre, completamente serviçal aos famintos setores do agronegócio, grande mídia, empresarial e seus enormes números de deputados. Essa opulenta máquina tem trabalhado a todo vapor com vistas a aprovar as ditas "reformas", sem diálogo com a sociedade civil.

As reformas são vendidas como condição necessária para superar a crise. Assim elas são uma ponte para o pós-crise, ou ainda representariam "a fase depois que a Crise passou" (BOBBIO 2004, p. 303). Para os mandatários não há outra alternativa, daí toda a retórica do medo caprichosamente preparada pela grande mídia, com a finalidade de azeitar as mentes mais distraídas. O pânico semeado alerta que, sem as reformas - trabalhista, previdenciária -, não haverá futuro, como se na cabeça deles houvesse uma preocupação com o passado ou presente de nosso país. Em síntese, para eles, o único remédio para a crise são as reformas.

A grande mídia tem se preocupado em noticiar diariamente os passos desse Brasil cambiante. Muito tempo tem sido gasto em denunciar o conluio entre partidos e alguns de seus políticos e as empresas. O aumento do desemprego e da violência se somam ao caldeirão de problemas que afligem a nação. Toda essa instabilidade instigada pela grande mídia encontra na necessidade das reformas, o seu remédio. Portanto, sob a retórica da "crise", o medo do futuro tem sido inculcado na cabeça dos brasileiros, cuja salvação possível passa pelas reformas.

\section{A CRISE DA REPRESENTATIVIDADE POLÍTICA}

A consequência da retórica midiática uma vez direcionada aos brasileiros, dá margem ao encorajamento de conformismos e naturalização dos problemas sociais e políticos. $\mathrm{O}$ sentimento de negação a tudo que diz respeito à política é evidente em nossa população. Nesse caso, ao tomar conhecimento da realidade nacional pela grande mídia, os brasileiros são estimulados à anemia política devido ao descrédito e desconfiança frente aos poderes da nação. Ao tempo em que, setores da sociedade civil organizada - sindicatos e movimentos sociais - também são apresentados de forma inconveniente e maléfica aos olhos do público. Por isso se forma o estereótipo segundo o qual esses movimentos são baderneiros, preguiçosos e foras da lei. 
O espetáculo dantesco no qual derrotou o Governo Dilma trouxe mais vulnerabilidade para a população brasileira, já que o legislativo e o judiciário foram os carrascos do processo. Ela sofreu o impeachment devido ao argumento falacioso denominado de "pedaladas fiscais", sendo que a grande maioria dos seus algozes - da câmara e do senado - estavam e estão envolvidos até o pescoço com denúncias, desmandos, roubalheira e rapinagem. Acontecimento esse que já entrou para a história dos anais da desonra nacional. O sentimento da imensa maioria dos brasileiros hoje é de desconfiança e descrédito sobre os três poderes. Por exemplo, juízes antes considerados irrepreensíveis e imparciais, hoje já são vistos como justiceiros apoiados pela grande mídia, menos preocupados com justiça do que com a fama. A tática da acusação de pessoas acompanhada do linchamento midiático antes da investigação, já não vem funcionando mais.

Contudo, o tempo gasto nas denúncias não tem sido o mesmo entre partidos e políticos. Em outras palavras, alguns partidos e seus respectivos políticos estão tendo uma atenção "especial” na hora da denúncia, o que inclui também o depoimento (verdadeiro ou não) dos delatores. $\mathrm{Na}$ forma espetacularizada pela qual algumas dessas delações são enfatizadas, a impressão que se tem é que aquilo que está sendo dito contra alguém ou grupo é verdadeiro. O resultado é que, quando assistimos os principais noticiários e abrimos determinados portais de notícias de grandes jornais vendidos como "imparciais", essas delações ganham destaque.

Isso resulta numa crise sistêmica de nossa democracia representativa. O perigo está justamente nessa forma degenerada de conhecimento da vida política, cuja origem já vem manipulada pela grande informação. Nesse caso, por um lado, conhecer significa se conformar à realidade cujo remédio são as reformas, já que o desemprego é fixado como um fato normal. Por outro lado, a resistência à crise é estimulada por algo vindo de fora, por exemplo, através de um fascista salvador da pátria, ou ainda por políticos que paradoxalmente se autodenominam "apolíticos”, e se arrogam, como grandes empresários que são, em colocar "as coisas no devido lugar".

Tudo muito bem abençoado por um tipo de esoterismo cristão presente até em cristianismos oficiais, cuja consequência é o de enfraquecer a força do cristianismo profético 
e comunitário, em vista da manipulação do indivíduo por meio de milagres fingidos, motivando-os para uma infantilização da fé. Esse tipo de esoterismo cristão, além de favorecer um enriquecimento obscuro de seus ministros, estão transformando os seus fiéis em verdadeiros “cabos eleitorais da fé”. Daí o crescimento vertiginoso de partidos políticos e seus respectivos deputados ultraconservadores ditos "cristãos", preocupados em serem “testemunhas da fé”, nas fronteiras da política.

\section{CONHECIMENTO E ENGAJAMENTO POLÍTICO PARA ALÉM DA CRISE}

A explicação da realidade local e global na forma como nos é presenteada pela grande mídia, exige-nos uma atitude de suspeita em vista de uma crítica desses conteúdos midiáticos. Isso implica numa forma diferente de compreensão dos fatos, pois o que nos é transmitido não pode ser encarado como verdade. São interpretações que atendem a castas privilegiadas. Por isso, tudo o que nos é transmitido via rádio, TV, jornal e suas respectivas páginas na Internet, passa por um rigoroso processo seletivo para atender a interesses determinados. Esses interesses são pactuados por famílias que sempre exerceram um poder de domínio econômico e político sobre a nação brasileira. Daí a satanização de pessoas, grupos e movimentos que não obedecem a essas cartilhas.

Em vista disso, podemos nos massificar conforme a fôrma e o padrão de exigência da mídia, ou podemos ousar e pensar diferente dessa informação que está sendo propagada. Podemos imaginar o mundo a partir da experiência da poesia e do rigor crítico da filosofia. Conforme Heidegger (1978, p. 55): "No poetar do poeta, como no pensar do filósofo de tal sorte se instaura um mundo, que qualquer coisa, seja uma árvore, uma montanha, uma casa, o chilrear de um pássaro, perde toda monotonia e vulgaridade". Portanto, a suspeita e a crítica da informação fornecida por esses grandes grupos midiáticos exigem de nós um esforço de compreensão diferente e ousado da história. Esforço no qual, por si só, impede que aceitemos passivamente interpretações monótonas e vulgares do mundo, e nos encoraja para pensar e agir diferente do que aí está. Já dizia Dom Helder (2009, p. 391):

Tu te ofendes

se eu Te disser

Revista Debates Insubmissos, Caruaru, PE. Brasil, v.1, n.1, jan./abr. 2018.

Endereço: https://periodicos.ufpe.br/revistas/debatesinsubmissos/ 


\title{
neverste 0 \\ Debates Insubmissos
}

\author{
que o mundo surge aos meus olhos \\ informe \\ dolorido \\ inacabado? $[\ldots]$
}

Nos dias de hoje é preciso saber julgar a realidade nacional, menos como um espectador passivo e mais como um militante político, que coloca o bem-estar geral acima de interesses particulares. No dizer de Gramsci (2011, p. 129), devemos agir menos como homem-massa e mais como homens-coletivos, conforme citação:

\begin{abstract}
Quando a concepção de mundo não é crítica e coerente, mas ocasional e desagregada, pertencemos simultaneamente a uma multiplicidade de homens-massa, nossa própria personalidade é compósita, de uma maneira bizarra: nela se encontram elementos dos homens das cavernas e princípios da ciência mais moderna e progressista, preconceitos de todas as fases históricas passadas estritamente localistas e intuições de uma futura filosofia que será própria do gênero humano mundialmente unificado.
\end{abstract}

Dentro de um ponto de vista semelhante, Freire (2011) nos adverte sobre a necessidade de abandonar uma condição de sermos perpetuamente comandados por uma elite predatória para sermos senhores e partícipes da história. A massificação, para Freire (2011), é um processo de adaptação e acomodação do ser humano à realidade. É o que ele denomina também de "consciência intransitiva" que é o momento no qual os seres humanos têm uma concepção ingênua do mundo, tornando-o cerceado e ajustado a situações estranhas e mantenedores da sua própria desumanização, conforme citação: "Daí que a massificação implique no desenraizamento do homem. Na sua 'destemporalização'. Na sua acomodação. No seu ajustamento" (FREIRE 2011, p. 59).

Contra conformismos resultantes de uma visão de mundo fixa, carente e acrítica, Freire (2006) propõe o conceito de conscientização. Tal conceito está inserido numa epistemologia que reúne saber, reflexão e engajamento político. Educar exige um esforço contínuo e em conjunto para transformar a história. Uma vez que as massas vão adquirindo um conhecimento crítico e reflexivo da realidade, elas podem romper com uma visão de mundo fabricada, ótica esta responsável pela manutenção da estrutura favorável às classes privilegiadas. Conforme Freire (2006, p. 30): “A conscientização implica, pois, que ultrapassemos a esfera espontânea de apreensão da realidade, para chegarmos a uma esfera 
crítica na qual a realidade se dá como objeto cognoscível e na qual o homem assume uma posição epistemológica".

O importante é entender que nada nesse mundo pode ser visto como realidades imóveis e acabadas, como se o processo histórico fosse compreendido semelhante a um rígido bloco de pedra. A epistemologia de Paulo Freire é parte de uma tradição do pensamento na qual insiste numa visão dinâmica do mundo. De acordo com essa concepção, o ser humano concreto é inacabado, indeterminado e inconcluso. Uma vez que ele utiliza o conhecimento de forma crítica e reflexiva, o mesmo é capaz de mudar o curso da cultura, pois a cultura assim como a história e a educação são resultados da ação humana no mundo. Para Freire (2006, p. 42):

No ato mesmo de responder aos desafios que lhe apresenta seu contexto de vida, o homem se cria, se realiza como sujeito, porque esta resposta exige dele reflexão, crítica, invenção, eleição, decisão, organização, ação... todas essas coisas pelas quais se cria a pessoa e que fazem dela um ser não somente adaptado à realidade e aos outros, mas integrado.

A integração à realidade abre espaço para a transformação da política como espaço do possível e do indeterminado. Em outras palavras, reconhecendo-se objeto de determinada situação histórico, o ser humano integrado a esse mesmo espaço tem a possibilidade de, em conjunto, humanizá-lo.

\section{A POLÍTICA COMO ESPAÇO DE HUMANIZAÇÃO}

Se o ser humano é capaz de transformar suas próprias criações, ele também pode humanizar a política uma vez que essa arte é parte constitutiva e essencial da vida humana. É evidente o desgaste do conceito de política no Brasil atual. Isso porque estamos confundindo o conceito de política com o que há de pior na vida pública: corrupção, tramas, armações, jogo de interesses, ambição desmedida e enriquecimento ilícito. O caminho contra esses preconceitos passa pela retomada da compreensão de política, uma vez que é do interesse das camadas privilegiadas que a apatia e a desesperança se instaurem na população. Assim sendo, e com o apoio da grande mídia, essas classes obesas têm trâmite livre para assegurar as mudanças que lhe são oportunas e favoráveis. 
A política na sua forma degenerada é apenas a arte da corrupção e do enriquecimento ilícito. Assim, o esforço pelo conhecimento dos problemas sociais fora da informação midiatizada, pode inspirar novos sujeitos para atuarem no processo de mudança: "Daí a relevância da política", relata Santos (2007, p. 14), "isto é, da arte de pensar as mudanças e de criar as condições para torná-las efetivas". A política também inspira resistência e luta contra os projetos desumanizadores que artificialmente se instauram.

Uma vez que somos gregários, não há como não participar da vida política. Se optarmos pelo isolamento ou neutralidade, estamos abrindo mão de nosso direito à participação numa sociedade democrática, e estaremos delegando a outros o direito de decidir por nós. Conforme Freire (2006, p. 19):

A neutralidade frente ao mundo, frente ao histórico, frente aos valores, reflete
apenas o medo que se tem de revelar o compromisso. Este medo quase sempre
resulta de um "compromisso" contra os homens, contra sua humanização, por parte
dos que se dizem neutros. Estão "comprometidos" consigo mesmos, com seus
interesses ou com os interesses dos grupos aos quais pertencem. E como este não é
um compromisso verdadeiro, assumem a neutralidade impossível.

Ao enfrentar os preconceitos e as desconfianças contra a política, Hannah Arendt 64 (2002) parte de dois pressupostos fundamentais sobre aquela arte. O primeiro é que: "A política baseia-se na pluralidade dos homens" (ARENDT 2002, p. 21). A política é um fato que se realiza entre as pessoas, já que nenhum humano pode realmente ser humano isoladamente. É por isso que a política é parte de um fazer humano, mas esse humano é concreto e gregário, ou seja, está em relação permanente com os outros. Contudo, uma vez gregários, os humanos são diferentes uns dos outros. É daí que podemos entender o segundo pressuposto segundo o qual: “A política trata da convivência entre diferentes" (ARENDT 2002, p. 21).

O problema é que a convivência entre diferentes nem sempre é pacífica. As paixões, ambições egoístas, inveja, violência, traições e crimes integram a convivência entre os humanos. Daí a necessidade de sabermos para quem a política está a serviço, para onde ela está sendo direcionada e por quem. Em tese, a democracia é "poder do povo", por isso esse sistema político deveria refletir as demandas e exigências da população. É preciso confiar em si mesmo, mas resistir em conjunto. Então, se os grupos menos privilegiados, que 
representam a grande maioria da população, não têm consciência e estímulo sobre o seu papel na vida pública, eles serão engolidos pela estrutura econômica e política dominante, que é o que estamos presenciando agora.

Arendt (2002) nos alerta sobre a necessidade de sabermos qual é o centro da política no contexto no qual fazemos parte. Se a política como está não atende aos anseios das classes desfavorecidas, então o seu curso tem que ser mudado. A política tem que ser reinventada a partir de outros atores hegemônicos. Essa visão dinâmica da política tem que se contrapor veementemente à visão degenerada da política como algo nocivo. Visão que é estimulada pela propaganda e noticiários. Conforme Arendt (2002, p. 45-46):

A política, assim aprendemos, é algo como uma necessidade imperiosa para a vida humana e, na verdade, tanto para a vida do indivíduo como da sociedade. Como o homem não é autárquico, porém depende de outros em sua existência, precisa haver um provimento da vida relativo a todos, sem o qual não seria possível justamente o convívio. Tarefa e objetivo da política é a garantia da vida no sentido mais amplo.

Desse modo, o conhecimento crítico que aprofunda a importância da política é essencial para enfrentar os preconceitos e falácias que obscurecem os valores dessa arte e, por isso, desencorajam nossa participação ativa na sociedade. Antes de ser sinônimo de corrupção e falcatruas, a política enquanto produção humana, deve ser vista como a arte de solucionar os problemas que ela mesma criou. A política não apenas estimula os conformismos e acomodações, mas ela encoraja, sobretudo, resistência e engajamento, para enfrentar crises e calamidades que ameaçam a convivência humana.

\section{CONCLUSÃO}

"Nas águas fortes", escreveu outra vez Dom Helder, "se refletem as grandes paixões eternas, encarnadas em nossos dias: a Fome, a Guerra, o Ódio, a Avareza, a Ambição" (CÂMARA, 2009, p. 335). Nos mares turvos do Brasil atual, essas "paixões eternas" estão ainda mais vivas e não menos obscuras são as informações delas distorcidas que chegam até nós. Entre a confusão dos poderes e a desqualificação dos grandes partidos, inclusive dos que se consideram de esquerda, o ethos das grandes corporações e suas "reformas" são os atuais atores do processo histórico. E ele não é nada comedido, conforme Milton Santos (2007, p. 
46): “A competitividade comanda nossas formas de ação. O consumo comanda nossas formas de inação. E a confusão dos espíritos impede o nosso entendimento do mundo, do país, do lugar, da sociedade e de cada um de nós mesmos".

Contudo, outros atores ainda não hegemônicos, têm batalhado diariamente por meio de uma contrainformação que envolvem blogs, agências de notícia, redes de relacionamento e sites de compartilhamento de vídeos, com o intuito de resistir ao status quo em vigor. Para que a solução das crises atenda aos menos favorecidos é necessário que a contrainformação seja compartilhada entre eles. Mais uma vez, organizações da sociedade civil ligadas a escolas, institutos, universidades, religiões aguerridas e libertárias, têm sido lugar de resistência ao promoverem debates, manifestações e pautas que resistem ao comando das ações do executivo, da maioria do legislativo e de setores do judiciário.

Essas organizações não são contra nenhuma reforma. Contudo, elas salientam com absoluta razão, que as reformas são importantes quando são frutos de uma construção coletiva lideradas por governos e representantes legitimados pela vontade popular. Não é o que ocorre com o Brasil de hoje em que permanece a política do toma-lá-dá-cá entre o executivo, membros do legislativo, empresas e o agronegócio. A ação política tem que trazer as classes menos privilegiadas para o centro. Uma forma disso se tornar realidade passa pela renovação e rearticulação dos partidos de esquerda. Historicamente, os partidos de esquerda construíram uma relação de confiança com os movimentos populares. Confiança abalada depois do episódio do mensalão e da operação Lava Jato.

Isso foi um prato cheio para a criminalização desses partidos e seus parlamentares, embora os que não se deixaram envolver em esquemas ilícitos também estão pagando o preço por pertencerem a tais organizações partidárias. Com eles, os movimentos sociais também entraram nessa pauta tenebrosa à ponto de se empreender uma relação de repugnância desses movimentos, aos olhos do público em geral. Nenhuma surpresa para quem exige que seu ponto de vista seja o único aceito, pois, dinheiro e informação midiática caminham juntas.

Daí que uma epistemologia crítica, além de descontruir a realidade imposta por uma determinada visão estática de mundo, é capaz de criar espaços de resistência em contraposição a essa então hegemônica. Permanecer na crise é não ousar conhecer e, por isso, 
se eximir do dever de não intervir na realidade. Como afirma Gramsci (2011, p. 163): “A identificação de teoria e prática é um ato crítico, pelo qual se demonstra que a prática é racional e necessária ou que a teoria é realista e racional".

\section{REFERÊNCIAS}

ARENDT, Hannah. O que é política? $3^{\mathrm{a}}$ ed. Trad. Reinaldo Guarany. Rio de Janeiro: Bertrand Brasil, 2002.

BOBBIO, Norberto, MATTEUCCI, Nicola e PASQUINO, Gianfranco. Dicionário de política. Tradução de Carmen C. Varriale [et. all]. 12 ed. São Paulo: Editora UNB Imprensa oficial, 2004 (vol. 1).

CÂMARA, Helder. Circulares conciliares: de 13/14 de outubro de1962 a março de 1964. Organização de Luiz Carlos Luz Marques e Roberto de Araújo Faria. Recife: CEPE, 2009.

FREIRE, Paulo. Educação e mudança. 29a ed. Rio de Janeiro: Paz e Terra, 2006.

FREIRE, Paulo. Ação cultural para a liberdade e outros escritos. $14^{\mathrm{a}}$ ed. Rio de Janeiro: Paz e Terra, 2011.

FREIRE, Paulo. Conscientização: teoria e prática da libertação. $3^{\mathrm{a}}$ ed. São Paulo: Centauro, 2006.

GRAMSCI, Antonio. O leitor de Gramsci: escritos escolhidos 1916-1935. Organização e introdução de Carlos Nelson Coutinho. Rio de Janeiro: Civilização Brasileira, 2011.

HEIDEGGER, Martin. Introdução à metafísica. $2^{\mathrm{a}}$ ed. Trad. Emmanuel Carneiro Leão. Rio de Janeiro: Tempo Brasileiro, 1978.

PEREIRA, Isidro. Dicionário grego-português e português-grego. $7^{\mathrm{a}}$ ed. Livraria $\begin{array}{llll}\text { Apostolado da } & \text { Imprensa: }\end{array}$ 